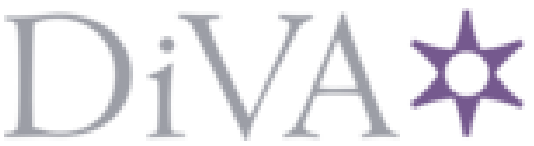

http://www.diva-portal.org

Postprint

This is the accepted version of a chapter published in Mediated Time: Perspectives on Time in a Digital Age.

Citation for the original published chapter:

Kaun, A., Stiernstedt, F. (2019)

Doing time / Time Done: Exploring the temporalities of datafication in the Smart Prison

In: Maren Hartmann; Elizabeth Prommer, Karin Deckner, Stephan Görland (ed.), Mediated Time: Perspectives on Time in a Digital Age (pp. 129-147). Basingstoke: Palgrave Macmillan

N.B. When citing this work, cite the original published chapter.

Permanent link to this version:

http://urn.kb.se/resolve?urn=urn:nbn:se:sh:diva-39389 


\title{
Doing time / Time Done: Exploring the temporalities of datafication in the Smart Prison
}

\section{Anne Kaun and Fredrik Stiernstedt}

\begin{abstract}
The aim of this chapter is to explore emerging temporalities linked to datafication through the lens of the smart prison. It is, hence, an exploration of time through a specific place that is put forth. Datafication and the consequent regimes of anticipation, prediction and pre-emption are increasingly discussed from a critical perspective in terms of discriminatory bias, processes of exclusion and as reinforcing inequality. At the same time, the prison and the criminal justice system are prime examples of implementing and emphasizing these emerging temporal regimes. However, there is currently little knowledge and research about how forms of anticipation, prediction and pre-emption are applied in the prison context. The chapter explores this connection by looking into current debates on establishing smart prisons. It concludes with the argument that rather than understanding prisons as removed and secluded from society, they are magnifying glasses for media-related social change and are crucial for exploring emerging mediated temporalities.
\end{abstract}

\section{Introduction}

'Doing time,' the idiom for serving a prison sentence, suggests an individual activity: time is what you do as a prisoner. On the other hand, accounts from prisoners themselves as well as other descriptions of prisons, underline that time is also what is 'done' to you: time is performed and situated not only by the individual prisoners but the prison as such is a facility that 'does time.' The expression underlines the point that time is an abstract category that needs enactment, that is situated and actively performed (Pentzold 2018). Time, within the prison, is created through meticulous time-based routines and technologies, "endless 
repetition, constant vigilance, interdictions, and rigid schedules" (Meisenhelder 1985), that serve the purpose of barring and replacing the ordinary life-time of the individual with the temporal regimes of punishment.

Prisons then are social institutions that create and uphold temporal regimes that are produced by rules and regulation and are enacted with the help of (media) technologies. The temporal regimes have bearing both for the individual prisoner and guard. This is, however, not unique for the prison context. On the contrary, the prison is a site, or a microcosm, through which such processes - representing society at large - can be observed and analysed as Michael Foucault (1975) has famously argued earlier.

Our starting point here is that the contemporary prison, as other social institutions, is deeply entangled with processes of datafication. The aim of this chapter is to study time and data through the empirical lens of the so-called 'smart prison.' The smart prison enhances some of the long-standing aspects of datafication within the prison - think of the fact that prisoners are referred to and identified as a numerical code rather than by name - enhancing control and surveillance. But the adaption of digital technologies and new forms of datafication within the 'smart prison' also contribute to an offsetting of temporality, towards prediction and pre-emption.

There are a host of initiatives and commercial 'solutions' for smart prisons. For example, in the Swedish context, the smart-building research platform, Memoori, has during the last years promoted the idea that "correctional facilities can be smart buildings too" (Memoori 2017). The article that mainly relies on examples of smart prison technologies developed by Johnson Controls discusses the advantages of smart technologies in the prison context, particularly for increasing and improving security and efficiency (Memoori, 2017), but also how smart technologies could be implemented for rehabilitation purposes to prepare prisoners for a future outside of the prison. The notion of the smart prison is, hence, 
about the introduction of smart devices for administrative, surveillance and rehabilitative purposes. Smart devices refer to connected, digital technologies that are to some extend operate interactively and autonomously.

Internationally, companies such as AgilFence, Johnson Controls and GTL offer 'smart prison systems' to their clients in the corrections industry. These companies are US-based, but work globally and the solutions and ideas promoted by them have impact in different parts of the world and in different prison systems. The use of smart technologies is also connected to the production, distribution and analysis of data. Hence, the process of datafication becomes closely intertwined with the so-called smartification of our societies.

Drawing on content from such plans and solutions for smart prison systems, this chapter aims to discuss dominant temporalities that emerge in the context of datafication. Datafication concerns processes of quantification and the transformation of evermore objects into data, as well as the automation of processes of judgements, evaluations, and decisionmaking (van Dijck 2014). Datafication is often described as a process that is invisible, abstract and hard to grasp. At the same time, developments linked to datafication, such as the use of artificial intelligence, big data analysis and automation based on AI, have been identified as some of the biggest innovations that potentially revolutionize the way we organize our societies, changes that are already underway in areas such as education, labour and warfare, through for example new forms of automation and algorithmic governance (Eubanks 2017; Kennedy 2016; Mosco 2017; O'Neill 2016). While datafication is currently discussed from all kinds of perspectives including its materiality - for example by Anna Reading (2015), who considers the fossils necessary for the production of our devices or by Jack Qiu (2016), who traces the labour exploitation necessary for producing digital data's hardware - there is comparatively little attention devoted to the question of how datafication is changing our perception of time. Working from the assumption that datafication has 
become an all-encompassing process, the chapter hence begins to theorize the question whether digital data imply a certain temporality. And if digital media have an Eigenzeit $^{1}-$ to use Wolfgang Ernst's (2013) expression - what are the societal and political consequences of emerging temporal regimes of datafication that include anticipation, prediction and preemption? These questions will be explored through the lens of the smart prison relating to and implementing datafication to efficiency and security, while keeping digital media practices of prisoners very limited.

The chapter develops an overview over emerging temporalities of datafication and identifies different temporal layers that partly contradict each other. Bringing the temporal layers into conversation with each other, we identify a strong desynchronization reinforcing inherent contradictions and ambivalence of the smart prison in particular and the datafied society at large.

\section{Exploring prison temporalities}

The chapter is based on exploratory work that is part of a larger project engaging with media technological innovation including processes of datafication through the lens of the prison. Prisons are chosen as an empirical focus both in their own right, as they sometimes work as testbeds for new technologies, but also due to the fact that datafication has a long and particular history within the prison, in which temporal regimes of prediction and pre-emption have been developing since the birth of the prison-system in the $19^{\text {th }}$ century. Furthermore, the prison, as a confined and secluded space, enables us to grasp more general social processes and media developments, also outside the prison walls, in a clearer way. The complex, large-scale and opaque relations that form in and through datafication, and the temporal regimes of this development, are concrete, visible and possible to be viewed in the social space of the prison, in ways that are difficult in other social settings. Relations between 
the surveyed and the surveyors, between freedom and restriction, between past, present and future, become more visible within the microcosm of the prison; as it is both radically different from and enacting norms and values of society in large. Prisons, we argue, hence crystallize social mechanisms and processes of change and make them visible and comprehensible. At the same time, the broader public has hardly any direct prison-related experiences and knows fairly little about the particularities of prison worlds.

\section{Temporalities of datafication beyond real-time and speed: anticipation, prediction and} pre-emption

Datafication can be - according to Mayer-Schönberger and Cukier (2013) - defined as the transformation of social action into quantified data, which allows for real-time tracking and predictive analysis. Digital media allow for the collection of data to a previously unseen scale ranging from emotions and sentiments expressed in social media to the character of relationships and purchasing behaviour (Mayer-Schönberger and Cukier 2013; van Dijck 2014). Van Dijck draws the conclusion the datafication has become a general organizing principle of society that builds on accessing, understanding and monitoring people's behaviour (van Dijck 2014). Looking more closely into these initial definitions of datafication makes clear that specific temporal imaginaries are fundamental to the process of datafication. Firstly, temporality is part of the definition of big data in terms of its real-timeness, namely the appeal to track practices, developments, environmental changes at high speed. John Cheney-Lippold (2017) in his book "We are data" underlines that velocity refers to the tracking rather than the analysis, as it takes time to compare the recorded data against previous data sets. Esther Weltevrede, Anne Helmond and Caroline Gerlitz (2014) have shown that the velocity of real-timeness is not as straightforward as it seems. They emphasize that different platforms and applications produce different temporalities and rhythms of real- 
timeness of devices and digital platforms. Hence, the notion of real-timeness of datafication is much more complex. Adding to these complications, we argue that the dominant temporal regimes linked to datafication are the seemingly future-oriented temporalities of anticipation, prediction and pre-emption that are a result of real-time tracking.

Anticipation in the context of datafication refers to the act of looking forward to a later action by relying on data of past behaviour. According to Ben Anderson anticipation is concretized through two "anticipatory practices": prediction and pre-emption (Anderson, 2010). Prediction refers to foretelling the future based on observations and experience, which is perfected in the context of datafication, since the likelihood with which a certain development will appear can be calculated on ever larger amounts of data. Pre-emption refers to practices and acts that prevent certain developments and behaviours from taking place. The aim is to forestall and preclude harmful threats. Based on predictive calculation, pre-emptive actions are also supposed to prevent concrete determinants from emerging in the first place. Following these definitions, the anticipatory practices of prediction is a presupposition for pre-emptive activities. Calculations based on big data that are at the heart of anticipatory practices seem to be addressing the future, but as Cheney-Lippold (2017) with reference to Oscar Gandy argues, prediction is inherently conservative and past-oriented as it is based on historical data. Anticipatory practices such as prediction and pre-emption, rather than being future-oriented, hence reproduce and reinforce assessments and decisions made in the past and contribute to a programmed vision of the future. Similarly, Rebecca Coleman (2018) takes the seemingly future-oriented temporalities of datafication as a starting point, but instead of focusing on the future or the past, she argues that anticipation, prediction and preemption constitute a multiplication of the present. She explores how various digital media produce different forms of the present including liveness, immediacy, but also bring the future into the present through anticipation and prediction. The temporalities of datafication are in 
that sense not about projecting a visionary future that needs to be actively constructed but instead reinforce established models and analyses. Rather than being concerned with the future, temporalities of datafication seem to be trapped in the past and present.

\section{Prison temporalities}

Similar to the dominant temporalities of datafication that are constructed around anticipation, prediction and pre-emption, the lived experience of time in the prison context seems to be trapped in a precarious form of the present. The experience of time and the loss of temporal autonomy is one of the major topics discussed in ethnographic accounts of life inside prison. In her seminal article, Medlicott (1999), for example, describes prison life as consisting of endless repetitions and the temporal ambivalence of the prisoner's experience of, on the one hand, suspended 'normal' lives, while, on the other hand, their bodies and identities age. Prisoners are losing their temporal autonomy as they are disciplined through time-based routines and completely exposed to external authority regulating their time use that is translated into excessive counting and observing of prisoners.

Meisenhelder argues that the structure of time in prison differs considerably from that of everyday life and is characterized by a suspension of the life outside, endless repetitions and strict schedules imposed on the inmates (Meisenhelder 1985). Foster (2016) explores the experience of waiting in a prison visitors' centre and refers to Sykes (1958) seminal notion of "pains of imprisonment" to capture what the wait encompasses for both visitors and incarcerated and how the painful temporality of the prison is extended beyond the walls into the lives of family members and friends of the incarcerated. Similarly, Turnbull (2016) refers to the lived experience of waiting in the uncertain and unpredictable context of detention centres as embodied experiences of insecurity and loss of temporal autonomy. Kotova (2015) develops the notion of temporal pains of imprisonment to analyse the experiences by female 
partners of long-term prisoners in the UK. She argues that the prison time extends beyond the visitation time and that research also needs to consider the deprivation of mundane family experiences as a consequence of the prison sentence. Kotova furthermore explores processes of adaptation and change over time that female partners go through in reaction to the prison sentence as a way to cope with experiences that have been described through temporal metaphors such as dead time, out of time, doing time representing the permanent state of waiting and suspension of life. It is hence not only prisoners, who are deprived of temporal autonomy, but also their families.

Armstrong (2015) argues that penal power of the prison is exactly the disciplinary function of waiting while the temporality of waiting in translated spatially into the prison cell. The prisoners are, however, not only punished through being put into the specific space of the prison (and the prison cell), but also in terms of compartmentalized temporality, i.e. time is sliced up into spatio-temporal boxes that line up into a linear narrative of punishment, prison sentence and rehabilitation. However, according to Armstrong (2018), the key point of the prison and other disciplinary institutions is not to produce the ideal subject as an actually existing one, but to reproduce the idea of this subject that is impossible to be realized. Hence, this impossibility of achieving the ideal subject becomes the productive motor of repetitive and eternal processes of control. The future in the prison context is often only implicated in terms of rehabilitation. Gomes Carvalho, Capela and Nunez (2015), for example, emphasize individuals' future time perspective (FTP) as having positive effects on the rehabilitation process.

In that sense, the temporalities of datafication and the prison world overlap in their focus on the present. At the same time, datafication complicates the present through providing different layers and regimes of the present within the prison context. This layering of the 
present of prison temporality through datafication will be explored in the following section through the notion of the smart prison.

\section{Smart prisons}

The initiative to discuss smart prisons, namely the wider introduction of smart or digital technologies in prisons and prison administration, is mainly driven by the prison industry and dominant actors in this field such as Johnson Controls, ST Engineering and GTL. The latter company (GTL - or Global Tel Link) is a US telecommunications company that was founded in 1980 to provide inmate calling services. Since then their scope has widened to include a range of services for communication and control within the prison environment. Johnson Controls and ST Engineering are more diversified conglomerates with a global reach that not only provide 'smartness' for prisons, but also develop solutions based on datafication and artificial intelligence for different social areas such as public transportations, military and industrial facilities. ST Engineering specifically has also been developing solutions for socalled smart cities, such as for example autonomous mobility, cyber security, and robotics. Smart cities are related to smart prisons insofar that they also represent an attempt to integrate digital networks and artificial intelligence into physical space (of a city). As is the case in 'smart cities,' the smart prison also rests upon restructuring the space - and its temporal regimes - through incorporating commercially developed technologies and to increase the corporate influence over the structuring of the prisons and the way that time is 'done' within them. If the scholarly literature on smart prisons is almost non-existent (to our knowledge there is no scholarly literature that addressees the smart prison and its political implications critically), there is however a growing body of work on the smart city (see for example Halpern 2015). 
Rob Kitchin (2014), for example, distinguishes between smart city conceptions that focus on a) pervasive and ubiquitous computing to monitor and structure the city and b) ICT enabled smart planning processes of the urban development that also include an emphasis on creation and knowledge. Both approaches build on the idea of implementing and integrating digital devices and infrastructures into the cityscape in order to produce large-scale data in real time. With the help of the harvested data, life in the city is supposed to be analysed in real-time, allowing new forms of government that are more efficient, sustainable, competitive, productive, open and transparent (Kitchin 2014). While the first conception of the smart city is characterized by short-term forms of anticipating and working towards a programmed future as discussed previously, the second approach to the smart city is more open to future visions that are not predicted based on big data analysis gathered through smart devices, but emphasize the open-endedness of city development with the help of smart technologies.

In the discourses about the coming of 'smart prisons' there are a similar division between enhanced possibilities for short-term forms of datafication emphasizing a programmed future on the one hand, and enhanced long-term models and programs for reform and 'normalization' for an open-ended future on the other. This follows from the two main and longstanding ideas of the prison as such: incapacitation and punishment on the one hand, and normalization, rehabilitation and readjustment, on the other. Following this, and similar to Kitchin, we hence distinguish between a focus on a) smart technologies that are based on ubiquitous computing with a focus on control, management and surveillance and b) an approach to smart development in the prison context that also includes the introduction of technologies for prisoner's rehabilitation.

\section{Smart surveillance and control - programmed vision of the future}


Although the use of digital media technologies in the prison context is still limited, there exists an increasing number of areas where such technologies are employed. The most common ways that digital technologies make an entry into the prisons are solutions offered by different companies that allow for ubiquitous computing to track, manage and control prison populations. Smart CCTV-systems that analyse behavioural patterns and that detect suspicious behaviour are one example thereof, while audio surveillance systems, which can analyse conversations within the prison and phone-calls to the outside world, are another. Singapore has started to work towards a "prison without guards," in which such technologies will be responsible for all the surveillance and control needed in the correctional facility. ${ }^{2}$ One example of smart digital technology in the prison context is Spartan by Guardian RFID (see figure 1). The android-based handheld device is equipped with radio frequency identification (RFID), Wi-Fi, push-to-talk as well as high-resolution imagining to be used to automate security rounds, for headcounts, inmate activity tracking and more. The website advertising the device suggests to "Centralize your inmate identification, security rounds, and activity logging into one powerful platform that integrates with your jail or offender management system. Maximize your defensibility, mitigate risk, and gain lightning-fast, realtime reporting with corrections most powerful Command \& Control platform.”

The website of Guardian RFID gathers not only various case trials and blog posts about the advantages of moving towards RFID logging and cloud services, it also collects the voices of administrators, wardens and Sheriff office officials. Most of the blog posts and user testimonies are concerned with the increased efficiency in controlling and surveilling inmates in real-time and with less error; including the following:

"Real-time Insight: 
'GUARDIAN RFID helps us make data-driven assessments about inmate observation and classification levels. We're measuring staff performance on our security rounds in real-time, which helps us manage compliance with jail standards.'

\section{Lt. Belinda Jackson}

Brazos Co. Sheriff's Office

Bryan, Texas" (https://guardianrfid.com/about)

Hence, it is not only the prison population that is controlled and supervised efficiently with the help of Guardian RFID, but also the guards and other members of staff. Besides selling specific devices, Guardian RFID also offers help with the complete outsourcing of server capacity, storage and processing of the data that are collected automatically. ${ }^{3}$

Common for the attempts to use digital technologies to survey and control prison populations is then that the collection of a range of different kinds of data in to common and remotely stored databases opens the possibility for analysing them in real-time, with the goal to predict and pre-empt unwanted behaviour among the interns. The Offender Management System developed by GTL for example promises to collect and handle "information on all aspects of an inmate's incarceration." For one thing these technologies create an increasing de-synchronization of the different speeds of prison time that are expressed in how smart technology is imagined to change the prison culture. For the individual inmate, the experience of doing time often is one of slowness, routine, waiting and the general - and intentionally created - feel of time (one's individual life-time) as inhibited or put on hold. The 'smart' system is imagined to increase, on the contrary, the pace of data collection and processing that is - and always has been - a part of how time is 'done' to the inmates. When procedures of gathering and making sense of data are increasingly automated and integrated in 'smart' systems, they can furthermore produce immediate results and actions. For example, a 
'deviant' pattern of movement within a 'smart' CCTV-system might lead to the automated response of doors locking. The fast pace of technological temporal regimens, then paradoxically, serves the purpose of increasing or at least maintaining the slowness, routine and inhibition of time that is the existential experience of the inmates; since the purpose of surveillance and control is to make sure that nothing (unexpected) happens. Unexpected means here that the prison institution is organized based on programmed future visions of correct behaviour of both inmates and guards that is enacted with the help of smart technologies. This programmed future vision of the prison relates to the dimension of smart surveillance and control and the increased importance of past actions for the patterning of the inmates' existence and for future predictions. Since a multitude of different kinds of data is not only collected but also stored and continuously analysed, and since smart system relies on machine learning from past patterns, this temporal dimension becomes increasingly important for the management of interns and the predictions of their future that is used in attempts to rehabilitate them and help them adjust to a future life outside of the prison. This is a point we will return to below.

\section{Smart normalization - open-ended future visions}

In contrast to technologies for the improvement of surveillance and control, there have been fewer attempts that approach digitalization of the prison from a perspective including smart technologies for rehabilitation and improvement of the everyday life of prisoners. The discourse on digital and smart technologies in the context of prisoners' use is mainly dominated by ideas to increase efficiency. For example, it is argued that self-service stations to let prisoners order certain goods or appointments with doctors or lawyers, which have been introduced for example in prisons in the UK and Belgium, increase processing speed and hence efficiency. In Belgium, authorities have experimented with a service platform called 
PrisonCloud that should standardize and gather all kinds of digital services including access to different media, self-service stations and contact with family and friends (Knight, Van and de Steen 2017). Often these initiatives are reproducing a short-term perspective of speed and efficiency in the everyday management of the prison and rarely include a long-term approach towards rehabilitation and normalization that includes digitalization and datafication to improve and enact an open-ended future vision for the prisoners (Knight 2018).

The criminologist Victoria Knight is one of the few who suggests such an approach. She defines the smart prison in a way that is radically different from the discourse prevalent among the international corporations discussed above. The smart prison for her is an environment that is user-focused, reduces limits to access digital technologies and instead provides a continuous flow of access-cell-workshops-education-leisure. The smart prison also uses the gathered data to inform management about the prison population for administrative and punitive purposes, but this is not the first and foremost priority (Knight 2018). She furthermore argues that digitalization can enhance digital literacy of prisoners, improve contact with the family and in general contribute to the well-being of the incarcerated and in that sense, reinstate temporal autonomy at least to a certain degree and opens up for a future outside of the prison and criminality. For the administration, digital technologies improve information sharing opportunities, public confidence and cost benefits. On the policy level, datafication of the prison potentially contributes to evidence-based decision-making (Knight 2018).

In this interpretation, the 'smart prison' is a facility that utilizes digital technologies and the connected process of datafication in order to contribute to the normalization approach that is a dominant prison regime in Norway, Sweden, Finland as well as Denmark and Iceland. The normalization approach emphasizes that life in prison should resemble as much as possible life outside of the prison walls, including stable structures of everyday life such as 
work and leisure activities. The approach is furthermore expressed in collegial prisoner-guard relations and a commitment to providing reliable social services including education and job training to prisoners and staff (Reiter, Sexton and Sumner 2018). To some extent, the normalization thesis is co-existing in the narratives of surveillance and control, while new 'smart' products and solutions are often marketed as both giving new opportunities for rehabilitation and control alike. Rehabilitation, for example, could take place through extended possibilities for interns to communicate with friends and loved ones. At the same time, the possibilities for control are deepening, for example through automated monitoring of calls or inmate messaging systems, which affords possibilities for offenders to keep in touch with people outside the prison through text-messaging, while simultaneously intensifying the possibilities of surveillance. The idea of normalization has always been strongly futureoriented, but not in a sense of programmed future of preventing unwanted behaviour such as fights, but enabling the prisoners to develop alternative future visions that depart from the criminal past.

The discussion above makes clear that there is a desynchronization between the shortsighted focus on programmed future visions and open-ended futures that are emphasized to different degrees through the temporal layers of digital media technologies of the smart prison. While digital technologies are increasingly used to make control, surveillance and administrative processes within the prison more efficient, prisoners themselves are in general still excluded from the advantages of using digital media. More concretely, datafication processes are implemented almost exclusively to control and survey prisoners. Digital media are rarely employed for rehabilitation and preparation for the life after the prison sentence while research increasingly discusses the many ways of how the use of digital media could contribute to normalization and reintegration (McDougall, Pearson, Torgerson and GarciaReyes 2017; Scharff Smith 2012). This desynchronization becomes particularly visible when 
comparing the advertisement for surveillance tools such as Guardian RFID, which focuses on technological innovation and the cutting-edge character, while the everyday of prisoners is characterized by the spatial environment deprived of digital media as pictured in figure 1 .

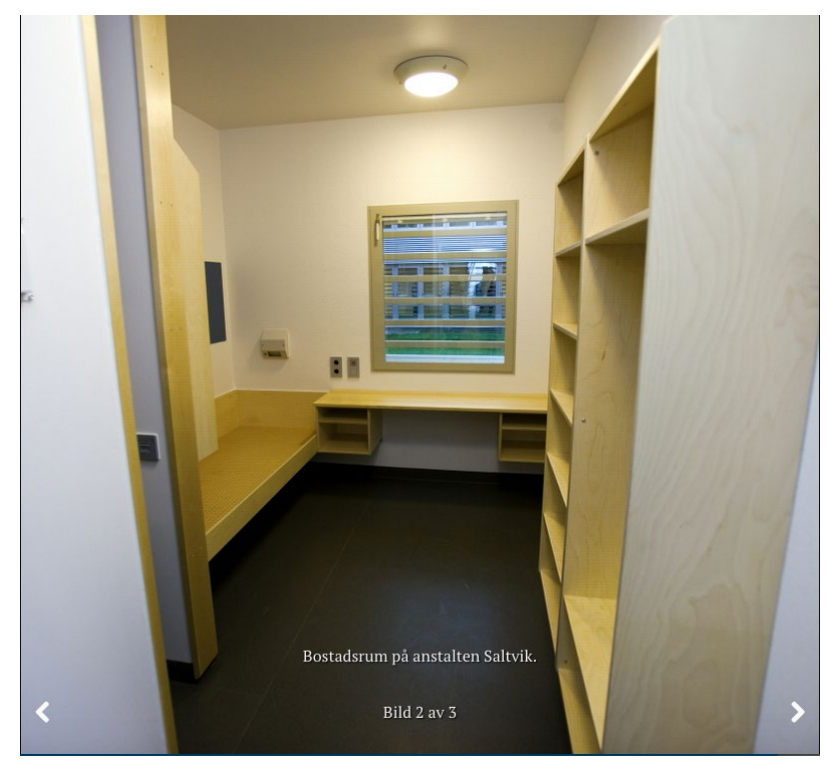

Figure 1: Average cell in one of the latest prison facilities built in Sweden (Saltvik), photograph published by the Swedish Prison and Probation Services on www.kriminalvarden.se.

It is only very recently that Swedish detention centres have started to allow access to social media in common rooms as depicted in figure 2.

Access is tested currently in one institution and is restricted to migrant detainees that have received the decision to be deported to their countries of origin. This desynchronization between the potentials of datafication and digitization for surveillance and control, on the one hand, and rehabilitation and normalization on the other, mirrors increasing divides in society in general. This increasing divide is not only situated on the level of access and literacy, but particularly on the level of control, agency and power over the data gathered. While users 
have access to a broad spectrum of digital applications and services, the consequences of datafication often remain opaque and hard to grasp in what Pasquale (2015) has termed the Black Box Society. In that context, critical scholars have pointed to the loss of control over our data in general, which is particularly palatable in the context of prisons. Prisoners are probably one of the best surveilled, datafied and documented population in society without having the choice of opting out because of privacy concerns. Privacy of prisoners is severely limited for prisoners for security concerns and as part of their punishment, even though prisoners retain some constitutional rights. If these fundamental rights are, however, in conflict with the regulations of the prison administration, the prisoners have the burden to show why the regulation is unreasonable and the constitutional rights should outweigh the regulation of the prison (Mirko Akrap 2016). In that sense, the prison becomes a space where new surveillance technologies can be tested without privacy concerns that user sometimes raise outside the prison walls. Prisons make visible a dystopian version of the future of datafication when constitutional rights and privacy concerns are not expressed and they become the obvious example of data injustice (Dencik, Hintz and Cable 2016) that is not removed from the society but that is its archetype. 


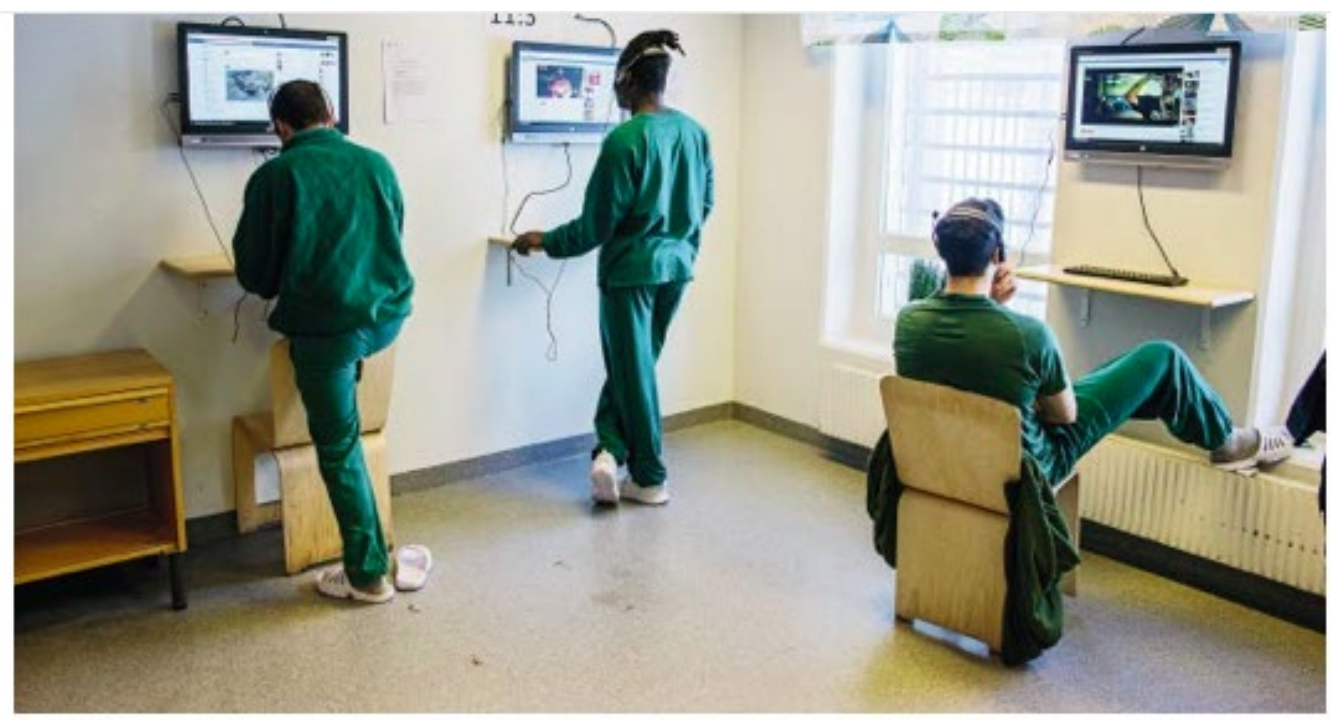

Figure 2: Omkrim magazine 2018, "Connected and save in detention”, photograph published by the Swedish Prison and Probation Services on www.kriminalvarden.se.

\section{Conclusion}

In the chapter, we have argued that prisons are vital to understanding datafied societies and in particular emerging temporalities of datafication, as they allow for the exploration of emerging temporal layers that are partly contradicting each other and are an expression of the ambivalent character of datafication. Datafication and digitalization in the prison context emphasize speed and acceleration as well as anticipatory temporalities of prediction and preemption rather than a temporality of longterm future orientation including ideas of rehabilitation. These data temporalities of the smart prison often underline ideas about the future that are focused on short-term results: They are about the pre-emption of conflicts in the prison building, controlling hot spots and the prediction of behaviour of prisoners, based on data of past behaviour and statistical models. Datafication in the prison strongly emphasizes the past that is folded into the present - what prisoners have done and are doing. This means that the use of digital technologies is focused on the control of unwanted behaviour by pre-empting it through predictive data analysis. This predictive data analysis 
based on past records and behaviour and hence bases the evaluation of the present on past actions and in that sense acts conservative rather than progressive. Rather than assisting prisoners with developing strategies for a future that is not decided upon yet, but that needs enactment and involvement, the focus is on preventing immediate harm.

Based on this discussion, we argue for a number of broader questions that need further exploration. Firstly, one can ask if datafication represents a shift in the temporal regime of the prison, from being a prime example of a modernist and future-oriented temporal regime of control and 'inspection' (such as in the Panopticon of Jeremy Bentham) to a more 'antimodern' temporality. If modernity and its institutions have emphasized ideas about the individual that is in the constant need of undoing and reinventing oneself, datafication, which emphasizes past behaviour, works towards the very opposite. Secondly, does datafication lead to a de-humanization of the prison and society in general? If we are increasingly relying on statistical models and delegate decision-making to algorithms, one could argue that not only the individual prisoner and his life history is disappearing, but that automation leads to a deprofessionalization of the staff, i.e. the guards and prison administration. This ultimately ends in a "prison without guards," as anticipated in Singapore. Thirdly, we can ask if datafication allows for a form of "deep pre-emption" that is not only based on observable past behaviour, but also includes the analysis of sentiments and affective and inner reactions from the interns. Through datafication the surveillance and control of emotional and psychological aspects of prisoners' lives could be enhanced in order to not only prevent physical escape attempts but also affective and "imaginary" ones.

All of these emerging questions are related to a paradox of datafication in the prison context. In order to allow for anticipatory actions in the form of prediction and pre-emption, prisoners need to act on and with digital media in order to produce data. Without any digital engagements, no data from which statistical models can be calculated, is produced. Hence, 
with the need for data, there might come more communicative freedom. This engagement paradox of datafication holds also true for the world outside of the prison. As Lina Dencik (2018) has argued, we are living in times of surveillance realism, where it is hard to imagine an existence without digital media that allow for datafication implementing different forms of corporate and state control. The convenience and promise of enhanced experiences holds users within the digital realm accepting the reality of datafication and surveillance, the data prison that we choose ourselves.

\section{References}

Anderson, B. (2010). Preemption, precaution, preparedness: anticipatory action and future geographies. Progress in Human Geography 34(6), 777-798.

Armstrong, S. (2018) The cell and the corridor: Imprisonment as waiting, and waiting as mobile. Time \& Society, 27(2), 133-154.

Carvalho, R. G., Capelo, R., \& Nuñez, D. (2018). Perspectives concerning the future when time is suspended: Analysing inmates' discourse. Time \& Society, 27(3), 296-311.

Cheney-Lippold, J. (2017). We are data: Algorithms and The Making of Our Digital Selves. New York: New York University Press.

Coleman, R. (2018). Theorizing the present: digital media, pre-emergence and infra-structures of feeling. Cultural Studies, 32(4), 600-622.

Dencik, L. (2018). Surveillance Realism and the Politics of Imagination: Is There No Alternative? Krise: Journal for Contemporary Philosophy(1), 31-43.

Dencik, L., Hintz, A., \& Cable, J. (2016). Towards data justice? The ambiguity of antisurveillance resistance in political activism. Big Data and Society, 3(2), 1-12. 
Ernst, W. (2013). From media history to Zeitkritik. Theory, Culture and Society, 30(6), 132146.

Eubanks, V. (2017). Automating inequality: how high-tech tools profile, police, and punish the poor: St Martin's Press.

Foster, R. (2016) 'Doing the Wait': An exploration into the waiting experiences of prisoners' families. Time \& Society, $0(0)$,

Foucault, M. (1975). Surveiller et punir: naissance de la prison. Paris: Gallimard.

Halpern, O. (2015). Beautiful Data. Durham: Duke University Press.

Kennedy, H. (2016). Post, mine, repeat: Social media data mining becomes ordinary. London: Palgrave Macmillan.

Kitchin, R. (2014). The real-time city? Big data and smart urbanism. GeoJournal, 79(1), 1-14. doi:10.1007/s10708-013-9516-8

Knight, V. (2018). Developing digital strategies: Becoming a smart prison. Paper presented at the ICT Workshop Stockholm, Stockholm.

Knight, V., Van, \& de Steen, S. (2017). Digitizing the Prison: The Light and Dark Future. Prison Service Journal(231), 22-30.

Kotova, A. 'Time ... lost time': Exploring how partners of long-term prisoners experience the temporal pains of imprisonment. Time \& Society, $0(0)$,

Mayer-Schönberger, V., \& Cukier, K. (2013). Big data : a revolution that will transform how we live, work, and think. Boston: Houghton Mifflin Harcourt.

McDougall, C., Pearson, D., Torgerson, D., \& Garcia-Reyes, M. (2017). The effect of digital technology on prisoner behavior and reoffending: a natural stepped-wedge design. Journal of Experimental Criminology, 13, 455-482.

Medlicott, D. (1999). Surviving in the Time Machine: Suicidal Prisoners and the Pains of Prison Time. Time \& Society, 8(2-3), 211-230. 
Meisenhelder, T. (1985). An essay on time and phenomenology of imprisonment. Deviant Behavior, 6(1), 39-56.

Mosco, V. (2017). Becoming digital: toward a post-internet society. Bingley: Emerald Publishing.

Nowotny, H. (1994). Time: The Modern and Postmodern Experience. Cambridge: Polity Press.

O'Neill, C. (2016). Weapons of math destruction: how big data increases inequality and threatens democracy. New York: Crown Publishing.

Pasquale, F. (2015). The black box society: the secret algorithms that control money and information. Cambridge: Harvard University Press.

Qiu, J. (2016). Goodbye iSlave: A manifesto for digital abolition. Urbana: University of Illinois Press.

Reading, A., \& Motley, T. (2015). The materiality of globital memory: Bringing the cloud to earth. Continuum - Journal of Media and Cultural Studies, 29(4), 511-521.

Reiter, K., Sexton, L., \& Sumner, J. (2018). Theoretical and empirical limits of Scandinavian Exceptionalism: Isolation and normalization in Danish prisons. Punishment \& Society, 20(1), 92-112.

Scharff Smith, P. (2012). Imprisonment and internet-access. Human rights, the principle of normalisation and the question of access to digital communications technology. Nordic Journal of Human Rights, 30(4), 454-482.

Sykes, G. (1958). The society of captives: A study of a maximum security prison. Princeton: Princeton University Press.

Turnbull, S. (2016). 'Stuck in the middle': Waiting and uncertainty in immigration detention. Time \& Society, 25(1), 61-79. 
van Dijck, J. (2014). Datafication, Dataism and Dataveillance: Big Data between Scientific Paradigm and Ideology. Surveillance \& Society, 12(2), 197-208.

Weltevrede, E., Helmond, A., \& Gerlitz, C. (2014). The Politics of Real-time: A Device Perspective on Social Media Platforms and Search Engines. Theory, Culture \& Society, 31(6), 125-150.

\footnotetext{
${ }^{1}$ Eigenzeit is here understood as a temporality that is inherent to the specific machine or media in contrast to what Helga Nowotny (1994) has described in her notion of Eigenzeit that refers to a form of "time proper" encompassing a certain combination of beliefs in relation to the future, past and present - a kind of structure of feeling in terms of temporality. 2 https://www.prison-insider.com (accessed 2017-04-13)

${ }^{3}$ https://guardianrfid.com/blog/why-jails-should-switch-to-mobile-inmate-tracking
} 